\title{
Effect of Parathion-Methyl on Amazonian Fish and Freshwater Invertebrates: A Comparison of Sensitivity with Temperate Data
}

\author{
Andreu Rico • Rachel Geber-Corrêa • Paola S. Campos • \\ Marcos V. B. Garcia - Andrea V. Waichman • \\ Paul J. van den Brink
}

Received: 25 July 2009/Accepted: 3 October 2009/Published online: 22 October 2009

(c) The Author(s) 2009. This article is published with open access at Springerlink.com

\begin{abstract}
Parathion-methyl is an organophosphorous insecticide that is widely used in agricultural production sites in the Amazon. The use of this pesticide might pose a potential risk for the biodiversity and abundance of fish and invertebrate species inhabiting aquatic ecosystems adjacent to the agricultural fields. Due to a lack of toxicity data for Amazonian species, safe environmental concentrations used to predict the ecological risks of parathion-methyl in the Amazon are based on tests performed with temperate species, although it is unknown whether the sensitivity of temperate species is representative for those of Amazonian endemic species. To address this issue, the acute toxic effect $\left(\mathrm{LC}_{50}-96 \mathrm{~h}\right)$ of parathion-methyl was assessed on seven fish and five freshwater invertebrate species endemic to the Amazon. These data were used to compare their pesticide sensitivity with toxicity data for temperate
\end{abstract}

\footnotetext{
A. Rico $(\bowtie) \cdot$ P. J. van den Brink

Department of Aquatic Ecology and Water Quality

Management, Wageningen University and Research Centre,

P.O. Box 47, 6700 AA Wageningen, The Netherlands

e-mail: Andreu.Rico@wur.nl

R. Geber-Corrêa · P. S. Campos · A. V. Waichman Universidade Federal do Amazonas, Instituto de Ciências Biológicas, Av. Rodrigo Otávio Jordão Ramos 3000, 69077-000 Manaus, Amazonas, Brazil

M. V. B. Garcia

Embrapa Amazônia Ocidental, Rod. AM-010, km 28, 69010-970

Manaus, Amazonas, Brazil

P. J. van den Brink

Alterra, Centre for Water and Climate, Wageningen University and Research Centre, P.O. Box 47, 6700 AA Wageningen,

The Netherlands
}

species collected from the literature. The interspecies sensitivity was compared using the Species Sensitivity Distribution (SSD) concept. The results of this study suggest that Amazonian species are no more, or less, sensitive to parathion-methyl than their temperate counterparts, with $\mathrm{LC}_{50}$ values ranging from 2900 to $7270 \mu \mathrm{g} / \mathrm{L}$ for fish and from 0.3 to $319 \mu \mathrm{g} / \mathrm{L}$ for freshwater arthropods. Consequently, this evaluation supports the initial use of toxicity data of temperate fish and freshwater invertebrate species for assessing the effects of parathion-methyl on Amazonian freshwater ecosystems.

Parathion-methyl [O,O-dimethyl $O$-(4-nitrophenyl) phosphorothioate] is a nonsystemic organophosphorous insecticide and acaricide used to control pests in a wide array of crops (ATSDR 2001). It is highly toxic to aquatic organisms and has been classified as "extremely hazardous" for the environment by the WHO (2004). Its use has been banned or restricted in 23 countries and its import is illegal in a total of 50 countries (PAN 2009). Despite the high toxicity of this compound, several studies have shown that parathion-methyl is intensively used among fruit and vegetable producers in floodplain areas of the Brazilian Amazon (Waichman et al. 2002, 2007). Amazonian farmers use higher application rates, more applications per production cycle, and shorter intervals between applications than recommended by the producing companies and the Brazilian Pesticides Law (Law 7.802/89). Waichman et al. (2007) pointed out that the lack of technical support and training of Amazonian farmers are among the causes of the indiscriminate use of this pesticide, which is frequently accompanied by incorrect practices (i.e., washing of application equipment in the river, inappropriate practices of container disposal, etc.). The incorrect use of pesticides 
is one of the main sources of pollution of aquatic ecosystems in the Amazon, posing a potential risk not only for the biodiversity and abundance of freshwater organisms but also for the sustainability and functioning of aquatic ecosystems. Consequently, there is a need to assess the ecological risks that the contamination of pesticides such as parathion-methyl represents to Amazonian freshwater ecosystems.

Due to a lack of site-specific toxicity data, in many tropical and subtropical countries like Brazil, the ecological risk assessment and the calculation of safe environmental concentrations for the control and monitoring of pesticides in the aquatic ecosystems have relied on European and North American single-species toxicity bioassays (Kwok et al. 2007; Lacher and Goldstein 1997). Consequently, acceptable environmental concentrations for pesticides (i.e., parathion-methyl) used in the Brazilian Amazon are based on the extrapolation of toxicity data derived in the temperate region; hence, differences in environmental parameters and species sensitivity are not being taken into account (Römbke et al. 2008). Differences in sensitivity between species should be assessed and incorporated in the risk assessment, because an extrapolation of temperate data to tropical conditions without a scientific base could lead to a potential risk for tropical freshwater ecosystems (Henriques et al. 1997; Lacher and Goldstein 1997). The differences in sensitivity to pesticides between freshwater species from different climatic regions have been already studied by several authors (Daam et al. 2008, 2009; Dyer et al. 1997; Kwok et al. 2007; Maltby et al. 2005). These studies could not demonstrate significant differences in sensitivity to pesticides between temperate and tropical species. Most of the tropical species used in this comparison, however, belong to the tropical region of Asia, and the uncertainty in the extrapolation of toxicity data calculated for species of the temperate region to protect Amazonian ecosystems still remains an open question. To address this issue, the present study aimed to estimate the effect of parathion-methyl on Amazonian endemic aquatic organisms (i.e., fish and freshwater macroinvertebrates) in order to study possible systematic sensitivity differences between Amazonian and temperate species. The results of this approach will be used to provide a recommendation on the applicability of temperate data in the derivation of safe environmental concentrations for parathion-methyl in the Amazon.

\section{Material and Methods}

\section{Acute Toxicity Tests}

The effect of parathion-methyl on Amazonian fish and macroinvertebrate species was assessed by performing
Table 1 Taxonomic classification, stage, length and weight (mean $\pm \mathrm{SD} ; n=10$ ) of tested fish and invertebrate species

\begin{tabular}{llll}
\hline $\begin{array}{l}\text { Class, order, family, } \\
\text { and species }\end{array}$ & Stage & Length $(\mathrm{cm})$ & Weight $(\mathrm{g})$
\end{tabular}
and species

Fish

Characiformes

Characidae

$\begin{array}{lccc}\text { Colossoma macropomum } & \text { Alevin } & 3.1 \pm 0.3 & 0.3 \pm 0.1 \\ \begin{array}{l}\text { Hyphessobrycon } \\ \text { erythrostigma }\end{array} & \text { (Sub) } & 4.1 \pm 0.5 & 0.9 \pm 0.3 \\ \begin{array}{l}\text { Paracheirodon axelrodi } \\ \text { Adult }\end{array} & \begin{array}{l}\text { (Sub) } \\ \text { Adult }\end{array} & 2.8 \pm 0.4 & 0.4 \pm 0.3\end{array}$

Lebiasinidae

Nannostomus unifasciatus

$\begin{array}{lll}\begin{array}{l}\text { (Sub) } \\ \text { Adult }\end{array} & 3.9 \pm 0.3 & 0.4 \pm 0.1\end{array}$

Perciformes

Cichlidae

Dicrossus filamentosus

(Sub) Adult

$3.0 \pm 0.5$

$0.3 \pm 0.2$

Siluriformes

Callichthyidae

Corydoras pygmaeus

(Sub)

Adult

$2.1 \pm 0.4$

$0.2 \pm 0.1$

Loricariidae

Otocinclus affinis

$\begin{array}{lll}\text { (Sub) } & 3.1 \pm 0.5 & 0.5 \pm 0.2\end{array}$

Crustacea

Decapoda

Palaemonidae

Macrobrachium ferreirai

Adult

$3.8 \pm 0.6$

$1.2 \pm 0.4$

Insecta

Coleoptera

Hydrophilidae

Hydrophilus sp.

(Sub) $\quad 0.8 \pm 0.1 \quad<0.1$

Hemiptera

Notonectidae

Buenoa unguis

Lepidoptera

Arctiidae

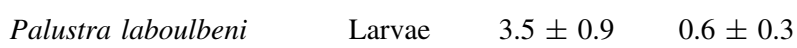

Gastropoda

Mesogastropoda

Ampullariidae

Pomacea dilioides

$\begin{array}{lll}\text { (Sub) } & 1.6 \pm 0.3(\varnothing) & 1.5 \pm 0.3\end{array}$ short-term toxicity tests $\left(\mathrm{LC}_{50}-96 \mathrm{~h}\right)$ with the species shown in Table 1. Fish individuals were purchased from a commercial source and were acclimatised for at least 7 days to laboratory conditions. Invertebrates were collected from uncontaminated shallow lakes, ponds or streams in the vicinity of Manaus, Brazil. Criteria used to select the 
studied species were based on availability through the year, ability to be kept under laboratory conditions, and body size (mainly for fish). The life-cycle stage, length, and weight of the individuals tested are given in Table 1 .

All tests were performed with an emulsifiable concentrate formulation of the commercial product Folisuper $600^{\circledR}$ (a.i. parathion-methyl $600 \mathrm{~g} / \mathrm{L}$ ). Stock solutions were made by diluting the test compound in distilled water and test media were prepared by diluting the stock solutions in tap water collected at the experimental facilities of Embrapa Amazônia Ocidental, Brazil. The tap water contained a low concentration of nutrients $\left(0.005 \mathrm{mg} / \mathrm{L} \mathrm{NH}_{4}{ }^{+}\right.$and $\left.0.05 \mathrm{mg} / \mathrm{L} \mathrm{PO}_{4}-\mathrm{P}\right)$, had an alkalinity of $2.2-2.3 \mathrm{mg} / \mathrm{L}$ of $\mathrm{CaCO}_{3}$, and had similar chemical characteristics to the stream water of fish and invertebrates habitats. Because Pomacea dilioides is not capable of living in extremely soft waters, the water used for these tests was collected from the uncontaminated pond from which they were collected. This water was previously filtered through a prewashed glass fiber filter (Whatman $\mathrm{GF} / \mathrm{C}$, pore size $=1.2 \mu \mathrm{m}$ ) and had a higher nutrient content $\left(0.3 \mathrm{mg} / \mathrm{L} \mathrm{NH}_{4}{ }^{+}\right.$and $\left.6.7 \mathrm{mg} / \mathrm{L} \mathrm{PO}-\mathrm{P}\right)$ and higher alkalinity $\left(63.1 \mathrm{mg} \mathrm{CaCO}_{3} / \mathrm{L}\right)$ than the tap water used for the rest of experiments.

All single-species tests were set up as static tests with a single application of parathion-methyl. Because parathionmethyl shows a fast dissipation under field conditions (Schulz et al. 2003), the exposure regime in static tests was considered more appropriate than a constant exposure. The tests were performed in 2.5 -L glass vessels with five treatment levels and an untreated control. All tests were done in triplicate $(n=3)$ with 10 individuals per test unit. Intervals between nominal concentrations in the test range differed by a factor of 1.5-2.2. OECD guidelines for testing the acute effects of chemicals on aquatic organisms (OECD 1992) were adapted to the natural conditions of the Amazonian species; that is, the water used in the experiments was similar to their habiting waters: soft water $(2-3 \mathrm{mg}$ $\mathrm{CaCO}_{3} / \mathrm{L}$ ), acid $\mathrm{pH}$ (5.5-6.5), and oxygen concentration higher than the $60 \%$ of saturation value.

The tests were conducted in a temperature-controlled room $\left(26 \pm 1{ }^{\circ} \mathrm{C}\right)$ with a light/dark regime of $12 \mathrm{~h}$ light and $12 \mathrm{~h}$ darkness. During the tests, the temperature of the media remained within the limits given in Table 2. In order to ensure a sufficient oxygen concentration in the test medium, an aeration system was installed in the experiments performed with fish and Macrobrachium ferreirai. The rest of invertebrate species are air-breathers or are capable of combining both respiration types so the tests were performed without aeration of the water. Dissolved oxygen concentrations and $\mathrm{pH}$ were measured with an YSI MODEL 550A meter and an YSI $100 \mathrm{pH}$ meter, respectively, at $2 \mathrm{~h}, 24 \mathrm{~h}, 48 \mathrm{~h}, 72 \mathrm{~h}$, and $96 \mathrm{~h}$ of exposure in at least one test unit per treatment level (including controls). Water hardness was measured before and after pesticide application and at the end of the experiment in some of the tests units, chosen randomly. Results of these measurements are reported in Table 2.

Table 2 Results of the acute toxicity tests with the insecticide parathion-methyl, volume of test units, and water parameters

\begin{tabular}{|c|c|c|c|c|c|}
\hline Species & $\begin{array}{l}\mathrm{LC}_{50}-96 \mathrm{~h}(\mu \mathrm{g} / \mathrm{L}) \\
(95 \% \text { confidence limits })\end{array}$ & $\begin{array}{l}\text { Test unit } \\
\text { volume }(\mathrm{L})\end{array}$ & $\begin{array}{l}\text { Temperature } \\
\left({ }^{\circ} \mathrm{C}\right) \\
\text { mean } \pm \mathrm{SD}\end{array}$ & $\mathrm{pH}, \min -\max$ & $\begin{array}{l}\mathrm{O}_{2}(\mathrm{mg} / \mathrm{L}) \\
\min -\max \end{array}$ \\
\hline \multicolumn{6}{|l|}{ Fish } \\
\hline Colossoma macropomum & $4983(4410-5631)$ & 2.5 & $26.4 \pm 0.6$ & $6.6-8.1$ & $4.2-6.4$ \\
\hline Hyphessobrycon erythrostigma & $7270(7053-7493)$ & 2.5 & $26.8 \pm 0.5$ & $6.6-8.0$ & $4.0-6.5$ \\
\hline Paracheirodon axelrodi & $6091(5487-6762)$ & 2.5 & $26.4 \pm 0.2$ & $5.3-7.2$ & $4.8-6.9$ \\
\hline Nannostomus unifasciatus & $5385(5018-5779)$ & 2.5 & $26.7 \pm 0.2$ & $6.1-7.8$ & $4.1-6.7$ \\
\hline Dicrossus filamentosus & $2900(2656-3166)$ & 2.5 & $25.9 \pm 0.2$ & $5.3-6.4$ & $4.0-6.0$ \\
\hline Corydoras pygmaeus & $4093(3823-4382)^{\mathrm{a}}$ & 2.5 & $26.0 \pm 0.2$ & $5.5-6.6$ & $4.0-6.1$ \\
\hline Otocinclus affinis & $6829(6110-7632)$ & 2.5 & $27.3 \pm 0.3$ & $7.1-8.5$ & $4.0-6.4$ \\
\hline \multicolumn{6}{|l|}{ Invertebrates } \\
\hline Macrobrachium ferreirai & $73.1(62.5-85.5)^{\mathrm{a}}$ & 2.0 & $27.7 \pm 0.4$ & $6.3-8.1$ & $4.2-6.2$ \\
\hline Hydrophilus sp. & $41.4(29.2-58.9)$ & 1.0 & $26.9 \pm 0.5$ & $6.6-7.4$ & - \\
\hline Buenoa unguis & $0.30^{\mathrm{b}, \mathrm{c}}$ & 1.0 & $26.4 \pm 0.4$ & $5.6-7.1$ & - \\
\hline Palustra laboulbeni & $319(263-387)$ & 1.0 & $26.6 \pm 0.5$ & $6.2-7.5$ & - \\
\hline Pomacea dilioides & $13607(12164-15221)$ & 1.0 & $26.5 \pm 0.3$ & $6.7-8.3$ & - \\
\hline
\end{tabular}

\footnotetext{
${ }^{a}$ Indicative because of cannibalism in controls (cannibalism is not indicated as a negative response)

${ }^{\mathrm{b}} \mathrm{LC}_{50}$ calculated at $72 \mathrm{~h}$ of exposure due to high mortality in controls

${ }^{c}$ Confidence limits not available due to singularity in regression model
} 
Mortality was chosen as an end point for assessing the effect of parathion-methyl on fish and macroinvertebrates. Lethal effects were monitored $2 \mathrm{~h}, 24 \mathrm{~h}, 48 \mathrm{~h}, 72 \mathrm{~h}$, and $96 \mathrm{~h}$ after exposure and dead organisms were removed from the experiment. For fish and macroinvertebrates, individuals were scored as dead when no response of any kind was observed for about $30 \mathrm{~s}$ after repeated tactile stimulation with a pair of metal forceps. Tests were rejected when mortality in the controls exceeded $10 \%$ for fish and $20 \%$ for invertebrates.

\section{Calculation of $\mathrm{LC}_{50}$ for Amazonian Species}

The $\mathrm{LC}_{50}-96 \mathrm{~h}$ values and their confidence intervals were calculated by a log concentration - probit effect regression model with the ToxRat Professional Version 2.07 program (ToxRat 2003), using the nominal concentrations calculated for the experiments. Abbott's formula was used by the program to correct for mortality in the untreated controls. Confidence intervals could only be calculated when at least one partial response between $0 \%$ and $100 \%$ effects was observed (singularity in regression model).

\section{Selection of Toxicity Data for Temperate Species}

The toxicity data of parathion-methyl for temperate species (27 fish and 17 freshwater arthropods) used in this study was the same used by Maltby et al. (2005), which had been collected from existing toxicity databases (e.g., www.epa.gov/ecotox and De Zwart 2002). In their study, single-species toxicity $\left(\mathrm{EC}_{50}\right.$ and $\left.\mathrm{LC}_{50}\right)$ data for fish and freshwater invertebrates with exposure duration between 2 and 21 days for fish and 1 and 7 days for invertebrates were selected. When more than one toxicity value was reported for the same species or various values were provided for a genus with no specific species name, the geometric mean was calculated.

\section{Comparison of Pesticide Sensitivity}

The sensitivity of freshwater Amazonian and temperate species to parathion-methyl was compared through the Species Sensitivity Distribution concept (SSD). The SSD can be defined as a cumulative distribution function of the toxicity of a compound to a set of species that have a common characteristic such as taxonomic group, habitat, or geographical region (Posthuma et al. 2002). The SSD model has been traditionally used in prospective risk assessment to calculate hazardous concentrations (HCs) concentration of chemical in the water that will affect a proportion $(p)$ of species ( $\mathrm{HC} p$ ). The cutoff value of the $5 \%$ of species of the left tail of the distribution $\left(\mathrm{HC}_{5}\right)$ has been traditionally used to derive safe environmental concentrations, assuming that ecosystems can tolerate a certain degree of chemical stress (Posthuma et al. 2002). In the present study, SSD analyses for fish and freshwater invertebrates were conducted according to the method of Aldenberg and Jaworska (2000) and performed using the ETX 2.0 software (Van Vlaardingen et al. 2004). The spreadsheet calculates the $\mathrm{HCs}$ for the $5 \%$ and $50 \%$ of species $\left(\mathrm{HC}_{5}\right.$ and $\mathrm{HC}_{50}$, respectively) and their $95 \%$ confidence limits. The model assumes a log-normal distribution of the introduced $\mathrm{L}(\mathrm{E}) \mathrm{C}_{50}$ toxicity data according to the formula

$f(x)=\frac{1}{\sqrt{2 \pi \sigma^{2}}} * \exp \left(\frac{-0.5 *(x-\mu)^{2}}{\sigma^{2}}\right)$,

where $\chi=\log \left(\mathrm{EC}_{50}\right.$ or $\left.\mathrm{LC}_{50}\right), \mu$ is the median of $\log \left(\mathrm{EC}_{50}\right.$ or $\left.\mathrm{LC}_{50}\right)$, and $\sigma$ is the standard deviation of $\log \left(\mathrm{EC}_{50}\right.$ or $\left.\mathrm{LC}_{50}\right)$.

The SSD was defined as the cumulative frequency distribution of toxicity data as follows:

$F(x)=\int_{\infty}^{x} f(x) d s$

Tests for log-normality were performed by means of the Anderson-Darling goodness-of-fit test. Normality of toxicity data was assumed at $p \geq 0.05$ (Posthuma et al. 2002).

The temperate invertebrates dataset was composed only by freshwater arthropods because large differences in pesticide sensitivity between arthropods and nonarthropods invertebrates are expected (Maltby et al. 2005). Therefore, only toxicity data for arthropods were included in the sensitivity distribution of Amazonian invertebrates, which are still the majority of the tested species because only one species is not an arthropod (Pomacea dilioides).

The sensitivity of Amazonian and temperate fish and freshwater arthropods was compared with the SSD concept. Sensitivity distributions were compared by using the two-sample Kolmogorov-Smirnov test, a nonparametric test that is used to assess whether two samples come from the same distribution, calculated with the SYSTAT 12 statistical package (SYSTAT 2007).

\section{Results and Discussion}

\section{Acute Toxicity Tests}

The results of acute toxicity tests performed in this study and test water conditions are shown in Table 2. The lower $\mathrm{pH}$ values corresponded with the measurements made right 
after application. Higher $\mathrm{pH}$ values could have been induced by the release of small amounts of ammonia present in the pesticide formulation and the rapid decomposition of dead organisms into the test units. The oxygen concentration of the test media seemed to depend on the size and metabolism of the organisms and the efficacy of the aeration system. Water hardness ranged from 2 to $3 \mathrm{mg}$ $\mathrm{CaCO}_{3} / \mathrm{L}$. A possible relationship between concentrations of parathion-methyl and the $\mathrm{pH}$, hardness, and dissolved oxygen concentration was not observed. For Buenoa unguis, mortality in controls became higher than $20 \%$ after the third day of exposure, forcing us to calculate the lethal concentration for $72 \mathrm{~h}$. Cannibalism was observed for Corydoras pigmaeus (fins bitten) and Macrobrachium ferreirai (damage produced by pincers) in controls; however, it was not counted as a negative effect because it occurred homogeneously in all treatments and mortality at controls did not exceed $10 \%$ and $20 \%$, respectively.

Of all species tested, B. unguis (Hemiptera) was the most sensitive, followed by Hydrophilus sp. (Coleoptera), M. ferreirai (Crustacea), and P. laboulbeni (Lepidoptera). Amazonian arthropods (insects and crustaceans) were found to be highly sensitive to parathion-methyl with acute $\mathrm{LC}_{50} \mathrm{~s}$ ranging from 0.3 to $320 \mu \mathrm{g} / \mathrm{L}$. These results are similar to other studies performed with temperate species exposed to this compound and different organophosphorous insecticides, probably due to the same mode of action of those pesticides (Maltby et al. 2005; Van Wijngaarden et al. 2005). Within fish, Dicrossus filamentosus was found to be the most sensitive species, followed by Corydoras pygmaeaus and the alevins of Colossoma macropomum. $\mathrm{LC}_{50}$ values ranged from 2.9 to $7.3 \mathrm{mg} / \mathrm{L}$ for Amazonian fish species. Pomacea dilioides (Gastropod) was found to be the most resistant species to parathion-methyl. They responded to the exposure to parathion-methyl by closing their operculum as an avoidance behavior, reducing their metabolic rate, exchange with the media, and, hence, their exposure. Several authors have already pointed out that this avoidance behavior is one of the main causes that influence the high tolerance of mollusks to pesticides (Daam et al. 2009; Schroer et al. 2004).

The internal validity of the results was acceptable because the confidence intervals of the toxicity values are relative small (lower and upper confidence limits differed by no more than a factor of 2 ), with the exception of $B$. unguis, whose confidence intervals could not be calculated due to the singularity of the regression model. On the other hand, the external validity of these results becomes difficult to assess because there are no previous ecotoxicological studies available with parathion-methyl for the tested species.

Comparison of Pesticide Sensitivity Between Amazonian Species and Temperate Species

The SSD curves for Amazonian and temperate freshwater species are shown in Fig. 1. The sensitivity distributions of temperate and Amazonian species did not show significant differences for fish (two-sample Kolmogorov-Smirnov test: $k=0.30, n_{1}=27, n_{2}=7, p=0.68$ ) or for arthropods $\left(k=0.63, n_{1}=17, n_{2}=4, p=0.10\right)$. The Anderson-Darling goodness-of-fit test was accepted for all four samples of toxicity data.

Table 3 shows the median values of $\mathrm{HC}_{5}$ and $\mathrm{HC}_{50}$ for temperate and Amazonian fish and arthropods with their lower $(95 \%)$ and upper $(5 \%)$ confidence limits. Median hazardous concentrations for temperate species appeared to be slightly lower than the values calculated for Amazonian species, with the exception of the median $\mathrm{HC}_{5}$ value for temperate arthropods; however, confidence intervals overlapped in all four cases. (a) Fish

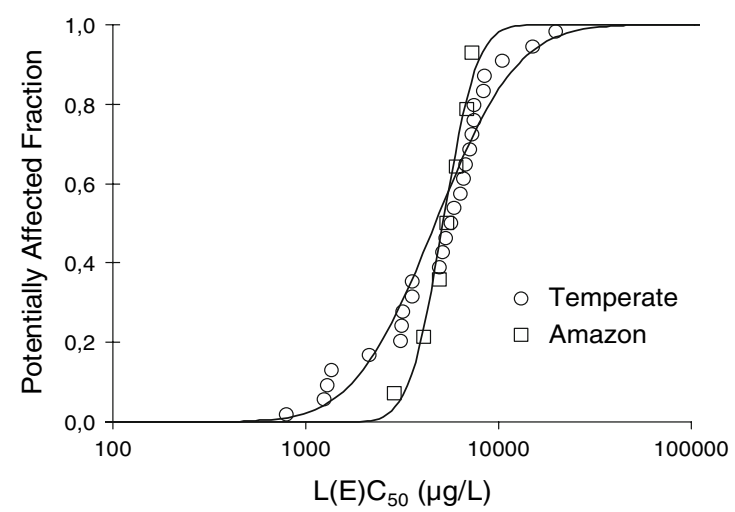

(b) Arthropods

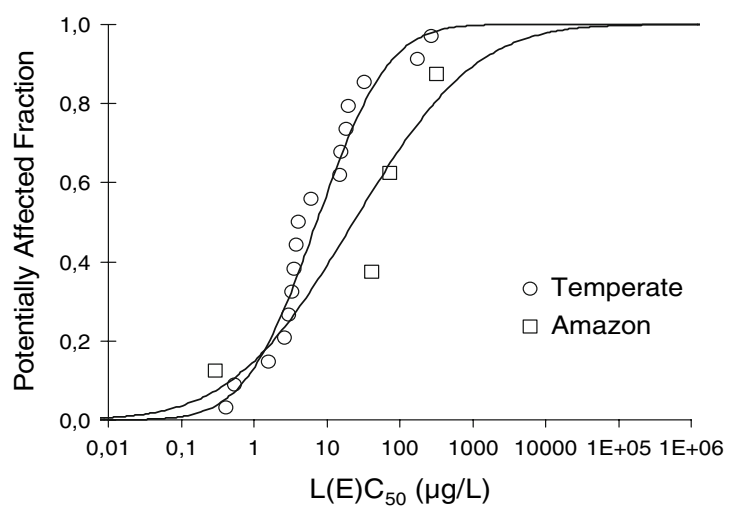

Fig. 1 SSDs for temperate (circles) and Amazonian (squares) species of $\mathbf{a}$ fish and $\mathbf{b}$ freshwater arthropods exposed to parathion-methyl 
Table 3 Median hazardous concentrations of parathion-methyl for $5 \%$ and $50 \%$ of species $\left(\mathrm{HC}_{5}\right.$ and $\mathrm{HC}_{50}$, respectively; in $\left.\mu \mathrm{g} / \mathrm{L}\right)$ and their lower $(95 \%)$ and upper $(5 \%)$ confidence limits for each SSD showed in Fig. 1

\begin{tabular}{lll}
\hline & Temperate & Amazon \\
\hline Fish & & \\
$\mathrm{HC}_{5}$ & $1308(827-1824)$ & $2963(1739-3839)$ \\
$\mathrm{HC}_{50}$ & $4697(3650-6044)$ & $5152(4074-6514)$ \\
Arthropods & & \\
$\mathrm{HC}_{5}$ & $0.37(0.09-0.96)$ & $0.09(0.00004-2.45)$ \\
$\mathrm{HC}_{50}$ & $7.26(3.43-15.4)$ & $23.2(0.66-814)$ \\
\hline
\end{tabular}

The results of the present study are in accordance with the study made by Dyer et al. (1997), who did not find significant differences between toxicity data for tropical and temperate fish exposed to four pesticides (carbaryl, DDT, lindane, and malathion) and two phenolic compounds (phenol and pentachlorophenol), and with the results of Maltby et al. (2005), who could not demonstrate significant differences between the SSDs constructed with aquatic arthropods from the tropical region and the temperate region for three insecticides (chlorpyrifos, fenitrothion, and carbofuran). These results seem to contradict the hypothesis that tropical organisms are more susceptible to pesticide exposure than their temperate counterparts due to an increase of temperature and metabolic rates (Castillo et al. 1997; Peters et al. 1997). This hypothesis has been supported by temperature-effect studies developed for a single species and might not explain adequately the variation of pesticide sensitivity between species from different climatic regions.

Kwok et al. (2007) conducted the most extensive comparison between temperate and tropical species sensitivity to chemical substances. In this study, SSDs were constructed for 18 compounds, including nutrients, metals, narcotics, and pesticides. For the studied pesticides, inherent sensitivity differences between temperate and tropical freshwater organisms could not be demonstrated; however, a safety factor of 10 was recommended when surrogate temperate Water Quality Criteria are used in tropical and subtropical regions. In the present study, according to the comparison of threshold concentrations $\left(\mathrm{HC}_{5}\right)$ derived from the SSDs, safe environmental concentrations for parathion-methyl constructed with temperate data resulted on a sufficient protection level to Amazonian species and, hence, the extrapolation factor proposed by Kwok et al. (2007) would not be necessary. However, according to the studies of Newman et al. (2000) and Wheeler et al. (2002), the number of Amazonian toxicity data included in the present study is rather small to ensure a minimal uncertainty in the SSD approach. Furthermore, considering the large diversity of fish and invertebrate species present in the Amazonian waters, species with different traits and adapted to specific environmental conditions (i.e., hypoxic or even anoxic water conditions) that could show different responses to exposure to parathion-methyl might be misrepresented in the Amazonian dataset used in the present study. Consequently, a wider array of toxicity studies for different Amazonian freshwater species should be performed in order to increase the confidence of the interspecies sensitivity comparison for parathion-methyl. On the other hand, several studies conducted in the temperate region have tested the potential of $\mathrm{HC}_{5}$ values derived from SSDs calculated with singlespecies laboratory toxicity tests in protecting freshwater communities (Maltby et al. 2005; Schroer et al. 2004; Versteeg et al. 1999). These studies demonstrated that the $\mathrm{HC}_{5}$ values (5\% of affected species) are protective of adverse effects in freshwater model ecosystems for the application of pesticides and are a useful tool for deriving safe environmental concentrations. However, this assumption has not been validated in the tropics, where there is a higher biodiversity and, hence, the number of species potentially affected is also higher. Therefore, there is a need to validate whether the threshold concentrations $\left(\mathrm{HC}_{5}\right)$ derived from the SSDs constructed with laboratory toxicity data are also protective for tropical freshwater ecosystems.

Daam et al. (2008, 2009) compared threshold concentrations derived from (semi-) field experiments in the temperate region and in the tropical region of Thailand for two pesticides: the insecticide chlorpyrifos and the fungicide carbendazim. It was concluded that temperate threshold concentrations show a sufficient protection level for tropical freshwater ecosystems. However, because our knowledge of tropical freshwater ecotoxicology is still very limited, it was recommended to conduct more model ecosystem studies with a wider range of pesticides on a larger geographical scale within the tropical zone. Accordingly, toxicity studies conducted under (semi-)field conditions, taking into account large assemblages of freshwater indigenous species and studying the actual fate and behavior of pesticides in the field, should be carried out in tropical areas such as the Amazon, where the intensive application of pesticides might pose a potential risk for the structure and sustainability of freshwater ecosystems.

\section{Conclusions}

Amazonian and temperate fish and freshwater arthropods show a similar sensitivity pattern to the insecticide parathion-methyl. It implies that the toxicity data calculated for temperate species (i.e., data from the US or European 
pesticide registration process) can be used in the derivation of safe environmental concentrations of parathion-methyl in the Amazon. However, the conclusions of this study should be treated with caution because they are based on a limited number of laboratory acute toxicity data. Further studies should be aimed at the validation of these conclusions with a wider array of acute and chronic toxicity data and studying the actual fate and effects of this compound under (semi-)field conditions in the Amazon.

Acknowledgments This research was jointly funded by CAPES and Wageningen University and Research centre. The authors are indebted to the scientists of the Departments of Entomology and Water Ecology of the INPA (Instituto Nacional de Pesquisas da Amazônia) for their kind help in the species identification. We also thank two anonymous reviewers who greatly improved the manuscript.

Open Access This article is distributed under the terms of the Creative Commons Attribution Noncommercial License which permits any noncommercial use, distribution, and reproduction in any medium, provided the original author(s) and source are credited.

\section{References}

Aldenberg T, Jaworska JS (2000) Uncertainty of hazardous concentrations and fraction affected for normal species sensitivity distributions. Ecotoxicol Environ Safety 46:1-18

ATSDR (Agency for Toxic Substances and Disease Registry) (2001) Toxicological profile for methyl parathion. Department of Health and Human Services, Atlanta, GA

Castillo LE, De la Cruz E, Ruepert C (1997) Ecotoxicology and pesticides in tropical aquatic ecosystems of Central America. Environ Toxicol Chem 16:41-51

Daam MA, Crum SJH, Van den Brink PJ, Nogueira AJA (2008) Fate and effects of the insecticide chlorpyrifos in outdoor planktondominated microcosms in Thailand. Environ Toxicol Chem 27:2530-2538

Daam MA, Satapornvanit K, Van den Brink PJ, Nogueira AJA (2009) Sensitivity of macroinvertebrates to carbendazim under semifield conditions in Thailand: implications for the use of temperate toxicity data in a tropical risk assessment of fungicides. Chemosphere 74:1187-1194

De Zwart D (2002) Observed regularities in species sensitivity distributions for aquatic species. In: Posthuma L, Suter GWI, Traas TP (eds) Species sensitivity distributions in ecotoxicology. Lewis, Boca Raton, FL, pp 133-154

Dyer SD, Belanger SE, Carr GJ (1997) An initial evaluation of the use of Euro/North American fish species for tropical effects assessments. Chemosphere 35:2767-2781

Henriques W, Jeffers RD, Lacher TE Jr, Kendall RJ (1997) Agrochemical use on banana plantations in Latin America: perspectives on ecological risk. Environ Toxicol Chem 16(1):91-99

Kwok KWH, Leung KMY, Lui GSG, Chu VKH, Lam PKS, Morritt D, Maltby L, Brock TCM, Van den Brink PJ, Warne MStJ, Crane M (2007) Comparison of tropical and temperate freshwater animal species' acute sensitivities to chemicals: implications for deriving safe extrapolation factors. Integr Environ Assess Manage 3:49-67

Lacher TE Jr, Goldstein MI (1997) Tropical ecotoxicology: status and needs. Environ Toxicol Chem 16:100-111

Maltby L, Blake N, Brock TCM, Van den Brink PJ (2005) Insecticide species sensitivity distributions: the importance of test species selection and relevance to aquatic ecosystems. Environ Toxicol Chem 24:379-388

Newman MC, Ownby DR, Mezin LCA, Powell DC (2000) Applying species sensitivity distributions in ecological risk assessment: assumptions of distribution type and sufficient number of species. Environ Toxicol Chem 19(2):508-515

OECD (Organization for Economic Cooperation and Development) (1992) Guidance document for aquatic effects assessment. OECD Environment Monograph 92. Environment Directorate, OECD, Paris

PAN (Pesticide Action Network) (2009) Pesticide database. http://www.pesticideinfo.org. Accessed June 2009

Peters EC, Gassman NJ, Firman JC, Richmond RH, Power EA (1997) Ecotoxicology of tropical marine ecosystems. Environ Toxicol Chem 16:12-40

Posthuma L, Suter GW II, Traas TP (2002) Species-sensitivity distributions in ecotoxicology. Lewis, Boca Raton, FL

Römbke J, Waichman AV, Garcia MVB (2008) Risk assessment of pesticides for soils of the Central Amazon, Brazil: comparing outcomes with temperate and tropical data. Integr Environ Assess Manage 4(1):94-104

Schroer AFW, Belgers D, Brock TCM, Matser AM, Maund SJ, Van den Brink PJ (2004) Comparison of laboratory single species and field population-level effects of the pyrethroid insecticide lambda-cyhalothrin on freshwater invertebrates. Arch Environ Contam Toxicol 46:324-335

Schulz R, Moore MT, Bennet ER, Farris JL, Smith S Jr, Cooper CM (2003) Methyl parathion toxicity in vegetated and non vegetated wetland mesocosms. Environ Toxicol Chem 22(6):1262-1268

SYSTAT (2007) SYSTAT software. SYSTAT Inc., Chicago

ToxRat (Toxicity Response Analysis and Testing) (2003) ToxRat Solutions GmbH. Aachen, Germany

Van Vlaardingen PLA, Traas TP, Wintersen AM, Aldenberg T (2004) ETX 2.0. A program to calculate hazardous concentrations and fraction affected, based on normality distributed toxicity data. Report No. 601501028/2004. RIVM, Bilthoven, The Netherlands

Van Wijngaarden RPA, Brock TCM, Van den Brink PJ (2005) Threshold levels for effects of insecticides in freshwater ecosystems: a review. Ecotoxicology 14:355-380

Versteeg DJ, Belanger SE, Carr GJ (1999) Understanding singlespecies and model ecosystem sensitivity: data-based comparison. Environ Toxicol Chem 6:1329-1346

Waichman AV, Römbke J, Ribeiro MOA, Nina NCS (2002) Use and fate of pesticides in the Amazon state, Brazil: risk to human health and the environment. Environ Sci Pollut Res 9:423-428

Waichman AV, Eve E, Nina NCS (2007) Do farmers understand the information displayed on pesticide product labels? A key question to reduce pesticides exposure and risk of poisoning in the Brazilian Amazon. Crop Protect 26:576-583

Wheeler JR, Grist EPM, Leung KMY, Morritt D, Crane M (2002) Species sensitivity distributions: data and model choice. Marine Pollut Bull 45:192-202

WHO (World Health Organization) (2004) The WHO recommended classification of pesticides by hazard and guidelines to classification. WHO, Geneva 